\title{
Representation and Self-Presentation of North Korean Defectors in South Korea: Image, Discourse, and Voices
}

\author{
Kyung Hyo Chun
}

\begin{abstract}
This article looks into how media representations of North Korean defectors reproduce the images of North Korean defectors, while paying particular attention to the contrasting voices of North Korean defectors which reflect self-presentation. The media-perpetuated image of North Korean defectors as displaced victims whose memories are mostly clustered around the oppressive regime fails to grasp the intersection of aspiration, determination, and agency of North Korean defectors. The self-presentation of North Korean defectors reveals that they are eager to be in charge of constructing and controlling their own images, which goes beyond hitherto nationalized, gendered, and ethnicized identities. Self-presentation, at the same time, is a product of strategic choices conditioned by social discourse and media representation.
\end{abstract}

Keywords North Korean defectors, media representation, self-presentation, identity, South Korea

\section{Introduction}

The number of the North Korean defectors residing in South Korea is approximately 34,000 as of the end of 2019, which is a rather small portion of the entire population of South Korea. Comparing this number to the number of international brides (1.6 million) and long-term foreign visitors living in South Korea (1.7 million) further demonstrates how few North Korean defectors there are in South Korea. Yet, the particular circumstance of political division between the two Koreas, the symbolic meaning of one nation, and the aspiration or expectation toward unification all add up to render North Korean defectors in South Korea as a group of significance. Most social attention on North Korean defectors is centered on adaptation and integration since they do not constitute a complete "other" to South Koreans. 
In addition to having no language barrier, North Korean defectors have a head start in that they are believed to share the alleged 5,000 years of Korean history and a priori Korean spirit with their fellow South Koreans. At the same time, it is noticeable that same language and cultural affinity between North Korean defectors and South Koreans does not always produce positive effects. Because of the presumed sharedness in historical experience and culture, North Korean defectors are considered qualitatively different from other groups of foreign origins, being regarded as an object for complete integration rather than that of effective adaptation (Choo 2006; Moon 2010; Choi 2012; Seo 2013).

This perspective also enabled the assumption that South Korea would be the final and inarguably optimal destination for North Korean defectors. In this line of thought, the act of crossing borders and setting foot on South Korean territory is considered achieving the ultimate goal, making the next step to becoming a "normal" South Korean citizen full integration, if not complete assimilation. Most policies for North Korean defectors aiming at successful adaption and integration reflect this widespread assumption. As opposed to this view, however, the North Korean defectors are found not only in South Korea, but also in other Asian countries, North America, and Europe. Furthermore, the fact that most North Koreans living in countries other than South Korea are actually talnam North Korean defectors (meaning they again "escaped" from South Korea after having had resided for an extended period of time in South Korea after defection from North Korea) illuminates the crevice between the prevalent popular belief of South Koreans and the real situations of North Korean defectors (Park et al. 2011; Jun 2012; Lee and Lee 2014).

The majority of South Korean people are well aware of the presence of North Korean defectors in South Korea due to media representation and government slogans, but very few of them have personal experiences of meeting them, not to mention having prolonged interactions in meaningful ways. Nonetheless, South Korean society seems to have a converging image of North Korean defectors which is constructed by media representation and policy discourses, while North Korean defectors secure few channels to have their voices heard.

With these particular circumstances in mind, this article asks the following questions: How much are North Korean defectors involved in the process of constructing their social images? How often do North Korean defectors have opportunities to have their voices heard? Are there existing differences between the dominant discourse on North Korean defectors and their self-presentation which reflect their motivations and intentions? If there is a gap between media representations and self-presentations, does it limit the capacity of North Korean defectors to live as legitimate citizens in South Korea?

Drawing on this, the following sections revisit the images and location of North Korean defectors in South Korean society by exploring how media represent them. A counter point is pursued by analyzing the content of interviews with 
North Korean defectors focusing on their own ways of presenting themselves. This article also attempts to shed light on the ambivalent state of North Korean defectors who are rendered as neither citizens like us nor refugees like them (Chung 2008; Yoon 2015), and on the alternative ways for understanding North Korean defectors. As a pilot study rather than a fully completed research project, this article contains interviews with only a few North Korean defectors to illuminate the point.

\section{Locating North Korean Defectors}

Current scholarship on North Korean defectors can be roughly grouped into three categories for convenience of analysis, although there exist considerable overlapping areas between them. The first, which forms the majority, centers on the discourse of adaptation and social integration of North Korean defectors within South Korean society (Kim 2016; Cho and Han 2017; Lee and Choi 2017; Seol and Song 2017; Kwon 2018). Literature in this category examines the state of as well as the multiple factors involved in the process of adaptation and integration, including South Koreans' perceptions toward North Korean defectors (Kwon 2011; Sohn and Lee 2012; Yoo and Lee 2014). Studies in this line usually employ both quantitative (survey) and qualitative (interview) methods, although the latter is more often than not used as a complimentary measure to the former. Research on adaptation and social integration is closely related to policy implications, sometimes involving funding and commissioning by the government or government-related institutions. This is largely due to the fact that information and data on North Korean defectors are primarily collected and tightly managed by the government. Diverse voices of North Korean defectors are hard to detect in these studies since the focus on policy implications often presumes homogeneity among North Korean defectors. Studies on acculturation, on the other hand, exhibit more interest for individual cases (Yoon and Park 2016).

While studies on adaptation and integration often approach North Korean defectors as part of a collectivity, the second group of research is keen to narratives generated by individuals. Given that the majority of North Korean defectors are women, it is not surprising that many studies pay attention to gender related issues in storytelling or memory-making processes on the part of North Korean defectors (Kim 2014; Cho 2015; Yang and Lee 2017). Along with women, psychology of the youth is another popular subject because young people, with their supposed malleability, are believed to best demonstrate the journey in which identity and perception of individuals undergo a series of change (Jung 2005; Baek and An 2016; Kim, Son, and Kim 2018).

Research on identity politics forms a significant part in this category. 
Identity formation, identity differentiation, identity transformation, and identity disorientations are among the popular subjects (Kang 2011; B. Lee 2014; Oh 2016). Although stories and memories of individuals can add flesh to the skeleton of the policy-centered discourse aforementioned, questions on representation and generalization can be raised against personalized accounts of North Korean defectors' experiences. Also problematic is that over-dramatized and sensationalized portrayals of the defection process might consolidate the image of North Korean defectors as victims.

A recent trend witnessed in scholarship on North Korean defectors is addressing North Korean defectors in the context of the transnational landscape and this forms the third category. Here, North Korean defectors are located beyond the insulated boundaries of nation-states to account for identity, psychology, adaptation, and so on (Han 2015; Chun 2018; Kang 2018). North Korean Diaspora (Park et al. 2011) is a seminal attempt published in the Korean language to shed light on the transnational aspect of the North Korean defector issue. In this coauthored volume, the pull and push factors for North Korean defectors to relocate to different corners of the world are well explored. Shin's (2019) study based on long-term fieldwork illustrates how North Korean defectors living in New Malden, United Kingdom expanded and renewed a sense of an "extra-territorial nation" through various interactions with South Koreans, other North Korean defectors, and foreigners.

While studies actively engaging in the discourse of transnationalism certainly have opened a forum for investigating the North Korean defector issue on a global level, this approach has a limitation in that it assumes a solid linkage between geographical locations and a level of transnationality. For example, North Korean defectors are regarded as transnational only when they "escaped" from South Korea in pursuit of other destinations. The loophole is that those who still remain in South Korea for various reasons seldom get attention in research focused on transnationalism. Under this tacit assumption, transnationality primarily involves physicality of geopolitics rather than encompassing aspirations and worldviews of people.

The present scholarship on North Korean defectors mentioned above has produced literature which understands North Korean defectors as either an undifferentiated collectivity to draw out huge policy implications or as individuated testimonials with fragmented sentiments. Being lost in these approaches are intersections and dynamics between agency and structure, between collective identity and personal identity, between history and psychology. To go beyond this limitation, this article juxtaposes analysis of the collective image of North Korean defectors made by South Korean media and that of the interviews with individuals North Korean. By so doing, not only the gap between media representation and self-presentation on North Korean defectors, but also "the third space" for addressing North Korean defectors can be articulated (Bhabha 2004). 


\section{Ambiguous Status of the North Korean Defectors: Legal, Cultural, and Social Considerations}

North Korean defectors have an ambiguous status on multiple levels. Article III of the South Korean Constitution declares that the Korean Peninsula and all the belonging islands are the territories of South Korea, which renders in principle the residents of North Korea as South Korean nationals. In 1997, the Law on the Protection and Settlement Support of the North Korean Defectors was implemented. This law defines North Korean defectors as someone having residential addresses, direct families, spouses, and jobs north of the Military Demarcation Line who defected from North Korea and not having acquired other nationality (Republic of Korea 1997). Hence, constitutionally and legally speaking, North Korean defectors have no problem obtaining Korean citizenship as long as the individual has not acquired other nationality previously. Unlike other foreigners, North Korean defectors instantly obtain South Korean citizenship without going through the naturalization process.

Although the South Korean Constitution does not acknowledge North Korea as a nation de jure, when it comes to international law, North Korea is a de facto nation that practically rules over its territory. Under this, North Korean residents are entitled to the status of quasi-foreigners. When they defect from North Korea, they acquire the status of mandate refugee according to the protocols of the United Nations High Commissioner for Refugees (UNHCR). However, the acknowledgement by the UNHCR regulations do not legally bind individual nation-states, as seen in the case of China where North Korean defectors are considered illegal immigrants, not refugees, and thus subject to deportation to North Korea. In sum, North Korean defectors go through a series of different statuses-North Korean citizens, mandate refugees, and South Korean citizens-during the process of defection. The South Korean government's recent decision to send two North Korean fishermen (allegedly defectors) back to North Korea raised a huge controversy and shed light on the ambiguous legal status of North Korean defectors which is full of room for different interpretations (Lee 2019).

Although North Korean defectors obtain South Korean citizenship and the related legality on arrival, they are clearly distinguished from South Korean residents. On arriving in South Korea, North Korean defectors remain in settlement adjustment centers (Hanawon) where they go through various programs promoting adaptation on political, economic, and social levels. Once they leave the center upon completion of the program, they become recipients of governmental welfare policies mandated by the Law on the North Korean Defectors which is firmly based on the discourse of integration. In fact, negative attitudes toward North Korean defectors often emerged from the question of fairness over the financial support and privileges granted them. Along with the settlement money from the government which is mandated by the Law on the 
North Korean Defectors, support for housing, job training, employment, and university admission is seen as "unfair," especially in the highly competitive South Korean society, and sometimes becomes a source of negative opinions toward North Korean defectors (Chun 2019, 96-98).

Socially, North Korean defectors still occupy an ambivalent position that clearly indicates the gap between reality and principle. Although many South Korean people express favorable sentiments toward North Koreans based on the discourse of "one ethnicity of five thousand years," when they find North Korean defectors in their neighborhood, very different attitudes are revealed. ${ }^{1}$ In other words, although South Korean people exhibit generous and inclusive attitudes for the abstract and unknown category of North Koreans as members of the same ethnic group, they are hesitant to share everyday life with them since they can pose a threat in "unfair" competitions given the many privileges entitled to them (Yoon and Song 2013). According to the Unification Perception Survey published by the Institute for Peace and Unification Studies (IPUS) at Seoul National University, although South Koreans consider North Korean defectors closer than either Ethnic Korean-Chinese or South Asians, when it comes to thinking of them as co-workers or future spouses, South Koreans express their intention to clearly set a certain social distance from North Korean defectors (Jung et al. 2019a).

\section{Almost Like Us, But Not Quite: Media Representation of North Korean Defectors}

While North Koreans are assumed to have "blood" relations as members of the same Korean ethnicity (hanminjok), at the same time, they are considered to be members of an enemy state in light of the division of the Korean Peninsula (see Lankov 2006). In other words, North Koreans are considered and treated sometimes as long-lost brothers, and at other times as evil twins depending on the focus of the circumstances. When it comes to North Korean defectors in South Korea, this ambivalence is all the more pronounced. While North Koreans are someone you need to live with in the undefined future, hence more abstract and generous attitudes are made possible toward them, North Korean defectors are also someone already here living with you, whose differences are considered uncomfortable and even disturbing.

For most South Koreans, encountering "real" North Korean defectors is only made possible through entertainment or current affairs television programs. In programs on current affairs, North Korean defectors appear as previous insiders of North Korea testifying on the horrible state of the secluded society, covering such topics as politics, human rights, and the dire economic situation. Entertainment shows provide more gender-skewed perspectives by giving 
the stage to young and attractive, mainly female, North Korean defectors and allowing them to talk about the lifestyle, customs, and popular culture of North Korea. In these shows, North Korean life is depicted as strange and outdated against the backdrop of South Korean life. When North Korean defectors introduce values, traditions, or habits that they had in North Korea in the media, the more strange they sound the more attention they get (Kang et al. 2017). Since something similar to South Korean lifestyle is not a good candidate for media attention, more dramatic and extreme cases are encouraged to get media hype (Oh 2016). While portraying North Korean culture and society this way, as SunMin Lee (2014) argued, female North Korea defectors are consumed not just as political defectors but also second class citizens in South Korea. The image of young and attractive North Korean women is rendered as exotic beauty through such media representation.

Media representation of North Korean defectors struggles with the same ambivalence South Koreans have toward them: although the primary focus is on showing the audience the contrasting difference between North Korean defectors and South Koreans in terms of lifestyle and customs, the belief in ethnic commonality also needs to be addressed reflecting the political and social needs within South Korea. To solve this cul-de-sac, one strategy is to define the North Korean lifestyle as behind that of South Korea by a couple of decades. In other words, even though contemporary North Korean culture appears to be strange to us, it might be possible to ring in with the old lifestyle and habits of our predecessors. This narrative assumes some level of similarity, but only in different time frames (Chun 2015, 288-89).

Placing the object of representation within a historically different time than our own is a very efficient strategy of othering the object. It does not reject the similarity, but only does so in a safe way. Johannes Fabian's (1983) concept of "denial of coevalness" finds its usefulness in this context. Fabian originally made the argument in the context of anthropologists and fieldwork. Once returning from the field, anthropologists write about their subject people often in such ways that the latter is placed in another temporal frame than the former's. This way of distancing, which Fabian called "denial of coevalness" has an effect of smudging political context and negating the historical importance of the anthropologist's experience. Representation of North Korean defectors achieved by South Korean media strongly resonates with Fabian's critique in that it also reveals power relations at play among groups of people with different political, social, and cultural assets to solidify the boundary and to block critical awareness. In the following section, I examine how the image of North Korean defectors are perpetuated with three keywords that are often used to describe them. 


\section{Defining North Korean Defectors in Social Discourses: Built-In Border Fence}

A level of consistency is detected in the way in which North Korean defectors are represented in South Korean society. Examining media representations of North Korean defectors in South Korean society reveals that, to make a huge and non-differentiating lump image of North Korean defectors out of people with various backgrounds and experiences, the following key words are liberally used: "displaced" status is emphasized to signify uprootedness of North Korean defectors; "community" is made important to understand the social nature of North Korean defectors; and "nationality" gets attention to measure the level of integration of North Korean defectors to South Korean society.

\section{Displaced}

As seen in the official title of North Korean defectors employed in South Korea, these people are understood as someone who "defected" from the place where they were born and raised. On the surface, there seems to be no problem in naming them in this way, sounding factual enough. However, the primary focus on "defecting" accentuates their state of "being displaced." Regardless that North Korean defectors either settle successfully in South Korea or defect again from South Korea in search of a better place in North America and Europe, the primary marker for North Korean defectors is firmly imprinted on the state of being "displaced."

The focus on displacement, in turn, provides a platform for adding negative aspects North Korean defectors might have: because they are displaced, they are unfamiliar with the new place, and this legitimizes negative qualifications such as incapability, sense of loneliness, inadaptability, and mental instability. It might be true that information on home is helpful when you are to understand other people, but essentializing a particular group based on their place of origin is a different matter. The problem with focusing on displacement is that it renders North Korean defectors passive victims of socio-politico-economic factors that forced them to leave, while little attention is paid to the motivation, intention, planning, calculation, and sentiments before, during, and after the defection.

\section{Community}

The communities related to North Korean defectors can be divided into two categories: ones before the defection, the others after the defection. The former includes communities based on familial ties, occupation, and regions with which they were affiliated in North Korea. The latter includes broker and religious groups that helped in the defection process, North Korean defector-based communities, and settlement center alumni communities. Media representations depict communities before defection more or less in a negative light to emphasize 
the distressing condition of North Korea and hence to legitimize the supremacy of South Korea. On the other hand, the communities after defection are portrayed in a relatively positive way focusing on their usefulness in accelerating the adaptation process.

Both cases share the same principle: the communities are considered to exist outside the North Korean defectors, and these communities wield formidable power onto them. No communities are free from changes and modification brought by the intersecting intentions and acts of the members. However, in most media representation of North Korean defectors, communities appear to be fixed and non-changing, and their significance is measured by whether they have positive or negative effects on North Korean defectors. This way of rigid configuration hampers analyzing the flexibility of communities as well as understanding transient appropriation of the communities on the part of North Korean defectors. Defection and adaptation is a long and complex journey. Paying attention to the process by which the relationships among members are defined and utilized will open up a window for better understanding the issue of agency on the part of North Korean defectors.

\section{Nationality}

The phenomenon of refugees is considered as a product of modernity in that discourses and policies on refugees seem non-separable from the concept of nation. Discourses on refugees concern their long and painful journeys with a series of events-being born and raised in a certain country, getting persecuted or oppressed, then being relocated to another country to be segregated or accepted only as second-class citizens.

Surveys on North Korean defectors often include questions on whether they identify as North Korean or South Korean. Sometimes it takes a euphemistic turn such as asking them which team they would root for in North-South Korea sports matches. Although these questions are designed to look into the selfidentification of North Korean defectors, it results in narrowing the field of national identity, fortifying the assumption that single-country belongingness at a given time is the norm. Criticizing the talnam phenomenon, a case in which North Korean defectors relocate to a third country after they spend some time settling in South Korea, as an act of betrayal is also in line with this perspective: if you dislike North Korea enough to leave for South Korea, then you should do whatever it takes to be a good citizen of South Korea. The widespread belief in patriotic sentiment to a single country as the norm even wraps this political idea with ethical concerns.

We can ask following questions in regard to this: how do North Korean defectors understand the single-nation-identity?; is it "normal" to have a sense of attachment only to a nation that provides one with a legal and institutional safe net?; is it legitimate to raise an ethical criticism for not having a sense of exclusive 
attachment to a single nation?; more fundamentally, how does one define one's own nation?

\section{Enunciating the Self: Can North Korean Defectors Speak?}

Years back, Erving Goffman (1959) developed the theory of impression management using the metaphor of life as theatre. According to him, just like actors on stage, individuals make conscious and unconscious efforts in their everyday interactions to present acceptable images of themselves to others while concealing information that might be in conflict with the images they want to deliver. With his signature dramaturgical approaches, Goffman employed such concepts as front stage and back stage to illuminate individuals' strategic choices and behaviors under different circumstances and audiences. Goffman's theory is crucial in that it registers the roles both agency and structure play in everyday life.

His analysis is insightful for the purpose of this article in regard to addressing the discrepancy as well as intersection between media representation and selfpresentation of North Korean defectors. Interviews with North Korean defectors enable us to look into their own ideas and intentions which is clearly different from prevalent media representations. At the same time, it is noticeable that the interviewees' stories are embedded with their intentions to present particular images-contrasting images to the widespread and negative representation of North Korean defectors-to the audience, the interviewer in this case.

\section{Interviews with North Korean Defectors}

As a pilot study, a total of four North Korean defectors were interviewed for this article and the number of interviewees are clearly not representative of the entire group of North Korean defectors in South Korea. On the contrary, the interviewees do not fit into the conventional category of North Koreans in terms of educational background, occupation, and social status. It is in fact considered a positive factor in seeking to pronounce some aspects that have been neglected or eschewed in the prevalent image of North Korean defectors. All four interviews were conducted as open-ended interviews, and the guidelines are as follow in Table 1.

\section{Self-Presentation of North Korean Defectors: Findings and Analysis}

In order not to disclose any private details of the interviewees, none of their personal information is revealed in the following section. Only their gender is acknowledged since all of them are female. In addition, no direct quotations of the interview content are presented here on specific request of the interviewees. 
Without quotation marks, however, efforts were made by the interviewer to deliver stories as they were told.

Interviews with North Korean defectors reveal that they have different foci from the media representation or policy discourse in presenting who they are and what they value. Throughout the interviews, the self-identification of interviewees was presented with the following points: desire to be acknowledged as fellow South Koreans, inclination to distance themselves from other North Korean defectors, willingness to take charge of their own lives, and everlasting longing for family reunion.

Table 1. Guidelines for the Open-Ended Interview with North Korean Defectors

\begin{tabular}{|c|c|c|}
\hline \multirow[t]{4}{*}{ Basic Information } & Personal & $\begin{array}{l}\text { Age, gender, areas of residence in North Korea, } \\
\text { occupation in North Korea, years of residence in } \\
\text { South Korean, areas of residence in South Korea, } \\
\text { current occupation in South Korea }\end{array}$ \\
\hline & $\begin{array}{l}\text { Defection } \\
\text { Process }\end{array}$ & $\begin{array}{l}\text { When, via which route, motivation, experiences of } \\
\text { overseas residence }\end{array}$ \\
\hline & $\begin{array}{l}\text { Affiliation with } \\
\text { North Korea }\end{array}$ & $\begin{array}{l}\text { Family members remaining in North Korea; methods } \\
\text { and frequency of contacting family members; method, } \\
\text { frequency, and amount of remittance }\end{array}$ \\
\hline & $\begin{array}{l}\text { Interaction with } \\
\text { Other North } \\
\text { Korean Defectors }\end{array}$ & $\begin{array}{l}\text { How often, with whom, for what purpose, through } \\
\text { what community }\end{array}$ \\
\hline \multirow{4}{*}{$\begin{array}{l}\text { Opinions on Media } \\
\text { Representation } \\
\text { of North Korean } \\
\text { Defectors in South } \\
\text { Korea }\end{array}$} & \multicolumn{2}{|c|}{$\begin{array}{l}\text { TV shows, programs, and movies about North Korean defectors } \\
\text { represented by South Koreans }\end{array}$} \\
\hline & \multicolumn{2}{|c|}{ TV shows and programs where the actual North Korean defectors appear } \\
\hline & \multicolumn{2}{|c|}{$\begin{array}{l}\text { Satisfaction/dissatisfaction about the way in which North Korean } \\
\text { defectors are represented, and why }\end{array}$} \\
\hline & \multicolumn{2}{|c|}{ Comments or suggestions for improvement } \\
\hline \multirow{6}{*}{$\begin{array}{l}\text { Understanding } \\
\text { Self-Presentation } \\
\text { of North Korean } \\
\text { Defectors }\end{array}$} & \multicolumn{2}{|c|}{$\begin{array}{l}\text { Communities or networks of the past and the present: types, purpose, } \\
\text { participation rate, satisfaction/dissatisfaction }\end{array}$} \\
\hline & \multicolumn{2}{|c|}{$\begin{array}{l}\text { Self-identity in relation to North Korea, South Korea, and/or a third } \\
\text { country (significance, attachment) }\end{array}$} \\
\hline & \multicolumn{2}{|c|}{ Attachment/meaning of North Korea and South Korea } \\
\hline & \multicolumn{2}{|c|}{$\begin{array}{l}\text { Evaluation of the experience of defecting from North Korea and living in } \\
\text { South Korea }\end{array}$} \\
\hline & \multicolumn{2}{|c|}{$\begin{array}{l}\text { Chance of returning to North Korea (when, under what condition, } \\
\text { reasons) }\end{array}$} \\
\hline & \multicolumn{2}{|c|}{ Country of residence for your children in the future } \\
\hline
\end{tabular}

Source: Author 


\section{Identity as North Korean}

When it comes to theory of identity, this article assumes the postmodern approach. Unlike the essentialist discourse which argues that identity has an unchanging and everlasting quality deep down in the unconsciousness, the postmodern approach to identity is based on constructionist views (Cerulo 1997, 31-93; Schachter 2005, 140-41). The postmodern tradition in identity theory has several branches depending on their emphasis on roles, performances, and power of knowledge, but they all agree that an individual is able to have multiple identities which are changed, contested, negotiated, appropriated, and manipulated depending on the circumstances and motivations.

When asking the interviewees to assess the percentage of their identity as North Korean defectors among various other identities that form an ego, all responded with a very low ratio, ranging between 5 and 10 percent. According to the annual survey conducted by IPUS on North Korean defectors, around 80 percent of the total respondents identified themselves as South Koreans rather than North Koreans (Jung et al. 2019b). Of course there are differences in question framing in that the IPUS's survey made the interviewees choose between North Korea or South Korea while this research asked for a percentage of significance of being a North Korean defector in forming the multi-layered identity for an ego.

It is noticeable that the stigmatic label of "North Korean defector" seems undying through the life of an individual. For example, even if someone defected from North Korea twenty years ago and has lived as a good South Korean tax payer for twenty years, society nevertheless sees the person as a North Korean defector, distinguished from born-to-be South Koreans. The low rate of identifying as a North Korean defector in the self-presentation of four interviewees, including one who has been in South Korea for only about one year, shows a huge contrast with the social perspective. When asked to elaborate on the reason for their low attachment to their North Korean origins, they said that since they were so busy adapting to South Korean society to become South Koreans, they do not have the luxury of considering themselves as someone other than South Korean.

Of course, there exists a crevice between such self-presentation and media representation, and this may in turn be a negative factor in confusing North Korean defectors' own identification. One of the interviewees told me that even though she does not consider herself a North Korean defector anymore, once people around her learn that she is from North Korea, their attitudes seem to be instantly affected by the fact. In turn, she feels discriminated against and isolated by such responses when she acknowledges the label of North Korean defectors attached to her, making it all the more salient, even though she herself refused to accept it as her major identity. 


\section{Community and Social Network}

It is clear that self-presentation or self-identification is not always consistent with the actual behavior of an individual. For instance, when asked how much they were involved with other North Korean defectors and received useful information from such networks, all interviewees replied none or minimal. However, when combining bits of stories here and there over the course of the entire interview session, it was obvious that they were having a considerable amount of interaction with other defectors and receiving significant amounts of useful information they trusted from their networks.

Then why do they minimize the real interaction in their direct and conscious self-presentation? It seems that they are very aware of how they are perceived by the interviewer (or other people) when they are seen as close to other North Korean defectors. As with the previous questions of rating their identity as North Korean defectors, the interviewees were keen to draw a line between them and other defectors to present themselves as South Koreans rather than someone from North Korea. When asked which community or group is most helpful or useful in their life, all interviewees pointed out occupational or professional groups that they were affiliated with in South Korea. This shows some consistency with the previous question in that they attempt to measure and manage the social distance from other North Korean defectors and thus manage the possible impression which may arise therein.

From an anthropological perspective, judging the factuality of the response is not of primary interest here. Rather, examining how the interviewees intend to interpret their images to others is more significant. For example, when tracking down the source of useful information the interviewee collected, it turned out to be from fellow North Korean defectors, although the interviewee said a few minutes ago that she was not in much contact with other North Korean defectors. In this case, the interviewee explained that the friends who shared the information happened to be North Korean defectors, but that does not mean that she deliberately built a relationship with North Korean defectors. Like this, all four interviewees sought to maximize their distance from other defectors, and this conscious self-presentation reflects a strong aspiration to control their own images which is different from the conventional image of North Korean defectors perpetuated by the media.

\section{Agency in Making Selections and Decisions}

Another contrasting point between media representation and self-presentation is the agency on the part of North Korean defectors. One of the key words that configures media representation of North Korean defectors is "passiveness." They are depicted as victims of political oppression, social control, and economic deprivation while in North Korea. With these images, North Korean defectors are considered people who escaped from North Korea due to insurmountable 
hardships and had no other option. They are recipients of government support following the beginning of a new life in South Korea. Thus, when they seem not to be successfully adapting to South Korea, society focuses on what kind of help was insufficient, not giving much attention to the North Korean defectors themselves. In both cases, the outer factors are measured as significant, rendering North Korean defectors as either victims or recipients.

The content of the interviews indicated, however, that the process of defection required a considerable amount of planning, determination, decision making, and compromises. In contrast to popular ideas, defection is not something improvised but a complex and deliberate process of information exchange among multiple players. The exchange of information is not balanced, of course, placing North Korean defectors in a very unfavorable position with a high risk of having their plans thwarted. Nevertheless, it is worth noting that the interviewees described the process and the aftermath of defection as results of their own decisions, and they were eager to be in charge of the situation, be it positive or negative (see also Yoon 2012).

The agency of the North Korean defector matters not only before and right after the defection, but also when it comes to the ultimate purpose of the defection. One of the echoing stories during the four interview sessions is that they came to South Korea not because they were starved and poor in North Korea but because they expected better opportunities and a brighter future in South Korea. One of the interviewees said that she might have lived an okay life in North Korea if she did not leave for South Korea. She added that she did not regret her decision though, because she still believed she would have a better future in South Korea.

Another interviewee confessed that she lived quite an affluent life in North Korea, but she decided to come to South Korea nonetheless since she longed for freedom. With freedom in making choices for her own life denied, it was not worth living, she said. She added that for her it was not political oppression or economic difficulties but a desire for personal independence that fueled her decision to leave North Korea. Here, in contrast to the media representation and dominant discourse that depict the North Korean defectors as victims and passive recipients, the interviewees considered themselves as active agents for their own life, being eager to take charge of the situation.

\section{Family and Diaspora}

One of the themes penetrating the past, present, and future of North Korean defectors appears to be family. When asked about an emotional attachment or the psychological distance to North Korea, challenges, and future plans in South Korea, and the possibility of a future visit/return to North Korea, all responses converged into the keyword of "family." The sense of attachment to North Korea might come from fond childhood memories, but a more fundamental factor 
lay in the fact that North Korea is where their loved ones are. The most difficult challenges in South Korean life include the absence of family and the concern about the wellbeing of family members remaining in North Korea. The only reason to visit North Korea in the future is also to reunite with their families.

Two of the four interviewees were cases of "chain defection," in which some family members were already settled in South Korea before the defection. These family members helped the interviewees come to South Korea with information on brokers and money through remittance. Even in these cases, the interviewees expressed their hopes or plans to bring other family members to South Korea in the future. Three of four interviewees said they were sending money to North Korean family members and were in contact with them on a regular basis via phone calls. The one who is not currently sending money to North Korea also said she planned to start the remittance once she found a better paying job.

Considering the images of North Korean society and family dynamics acquired through South Korean education on and media depiction of North Korea, one might think the kind of family relationship familiar to us is nonexistent in North Korea: it is a highly controlled society where the political party overrules the traditional family relationship, and individuals are trained to watch their own family members to maintain the socialist order. The interviews, however, show that the emotional importance placed on family is similar between the two Koreas. Furthermore, the North Korean defectors considered themselves in a similar vein with families who were separated by the Korean War (isangajok). Just like the separated families who cannot be with their loved ones due to the division of the Korean Peninsula, North Korean defectors, too, are suffering due to the hostile political circumstances between the two Koreas.

\section{Conclusion: Identity, Self-Presentation, and Society}

The number of North Korean defectors is a small fraction of the entire population of South Korea, and few South Koreans actually interact with North Korean defectors in their everyday lives. Nevertheless, people seem to share a certain image of North Korean defectors that have been represented and reproduced by the media. Criticisms of the television programs where North Korean defectors testify about the abysmal state of North Korean life and oppressive political regime are related to the perpetuation of negative images of North Korea. Circulating incorrect or exaggerated information on North Korean society is problematic considering the inter-Korean relationship and future unification. Just as problematic, although few people seem to care, is the social image of North Korean defectors portrayed by such programs.

Media representation of North Korean defectors in South Korea disseminates the following images: people who suffered from political oppression and 
economic poverty under a dehumanizing regime, people distinguished from South Koreans due to different lifestyles and value systems, people making a living by blaming their place of origin using incorrect information or exaggerated stories, and people earning fame by rejecting and tainting their past. While these images are reproduced and perpetuated, news on dire incidents, such as those who committed suicide after losing lots of money to scams or a family suffering a tragic end after an unsuccessful adaptation, become another path for South Koreans to realize the existence of North Korean defectors.

Real life for the 34,000 North Korean defectors can be found somewhere between the dramatized images and extreme tragedies. Unnoticeable they might be, they are still managing everyday life by struggling between the familiar and the new, different systems, values, and expressions. What this article attempts to show is that their own images, their self-presentation can be far different from what media representation has been conveying to most South Koreans. The images of North Korean defectors might be more complex and multilayered than the society believes them to be. For sure, it is not to say that North Korean defectors' self-presentation is closer to the reality per se. As Goffman's analysis of everyday presentation of self stipulates, self-identification and related conversation and behavior is the product of strategic choices which in turn fashioned individual intention as well social structure. Hence, the point of this pilot study lies in calling for a more nuanced and multifaceted approach in addressing North Korean defectors' lives in South Korea.

As mentioned in the beginning, this research is not an attempt to induce representability or generalizability of North Korean defectors as a whole. Rather, it has intended to reveal different angles than the hitherto circulated images of North Korean defectors by paying attention to their own self-images and voices, while keeping in mind that those self-presentations are also social constructs. The purpose of this article is limited in scope and scale for sure, but the effect does not necessarily have to be. As a pilot study on the identity and image of North Korean defectors, it awaits more active and productive discussions on the topic in the near future.

\section{Notes}

1. Some scholars argue that popular belief in the idea of "one nation of Korean people" is not so much about fictive blood as it is about a long history and culture of the Korean people. See Han 2007, 19-22. 


\section{References}

Baek, Seung Dae, and Tae Jun An. 2016. "Cheongsonyeonui gungminjeongcheseongi tongiruisige michineun yeonghyang" [The Influence of Adolescents' National Identity on Their Unification Consciousness]. Yeollingyoyugyeongu [The Journal of Yeolin Education] 24 (1): 39-58.

Bhabha, Homi K. 2004. The Location of Culture. London: Routledge.

Cerulo, Karen A. 1997. "Identity Construction: New Issues, New Directions." Annual Review of Sociology 23: 385-409.

Choi, Won-O. 2012. "Damunhwa sahoewa talbugijumin: diaseuporajeok gwanjeomui jeogyongeul tonghan ihae" [Multicultural Society and North Korean Defectors: Understanding through a Perspective of Diaspora]. Tongirinmunhak [The Journal of the Humanities for Unification] 54: 257-83.

Cho, Choon Bum, and Ki Ju Han. 2017. "Bukanitaljuminui ingusahoehakjeok teukseonge ttareun Namhansahoe jeogeungjeongdoui chaiwa Namhansahoe jeogeungsiltae" [Differences in Social Adjustment of North Korean Refugees According to Demographic and Social Characteristics and Social Adaptation in South Korea]. Damunhwawapyeonghwa [Multiculture \& Peace] 11 (1): 271-92.

Cho, Young Ju. 2015. “Bukanitaryeoseongui gusuljeollyakgwa damnonjeok suhaeng: eomeonidoegigyeongheomeul jungsimeuro" [Narrative Strategies and DiscursivePerformative in North Korean Refugee Women's Oral History: Focusing on Mothering]. Bukanyeonguhakoebo [North Korean Studies Review] 19 (1): 309-38.

Choo, Hae Yeon. 2006. "Gendered Modernity and Ethnicized Citizenship: North Korean Settlers in Contemporary South Korea." Gender and Society 20 (5): 576-604.

Chun, Kyung Hyo. 2015. "Danilminjokgwa damunhwajuui saieseo Bukan barabogi: gojeongdoen yeoksasogeseoui tajahwa hyeonsangeul jungsimeuro" [Perspectives on North Korea between Same-nation-ness and Multiculturalism: Otherization in South Korea]. Sahoegwahagyeongu [Social Science Studies] 23 (1): 274-300.

Chun, Kyung Hyo. 2018. "Site for Multivocality: Locating Overseas North Korean Defectors." Tongilgwa Pyeonghwa [Unification and Peace] 10 (2): 363-95.

Chun, Kyung Hyo. 2019. "Jeokgeukjeok pyeonghwaroseoui gongjonui gachi” [Toward Active Peaceful Coexistence]. Tongilgwa Pyeonghwa [Unification and Peace] 11 (2): 75-106.

Chung, Byung-Ho. 2008. "Between Defector and Migrant: Identities and Strategies of North Koreans in South Korea." Korean Studies 32: 1-27.

Fabian, Johannes. 1983. Time and the Other: How Anthropology Makes its Object. New York: Columbia University Press.

Goffman, Erving. 1959. The Presentation of Self in Everyday Life. New York: Anchor Books.

Han, Kyung-Koo. 2007. "The Archaeology of the Ethnically Homogeneous Nation-State and Multiculturalism in Korea." Korea Journal 47 (4): 8-31.

Han, Mi Ra. 2015. “Talbugyeoseongui chogukgajeok eomeoni gyeongheom” [Transnational Mother Experience of North Korean Women Defectors]. Damunhwawapyeonghwa [Multiculture \& Peace] 9 (2): 160-78.

Jun, Myung Hee. 2012. "Migugeuro gan talbukjadeurui jeongchakgwa jeogeunge gwanhan jiljeok yeongu" [North Koreans' Lives in the United States]. Hanguksahoebokjihak [Korean Academy of Social Welfare] 64 (4): 89-111. 
Jung, Dong Joon, Sun Kim, Hee-jung Kim, Yong-woo Na, In-chul Moon, Young-hoon Song, Gyubin Choi, Kyunghoon Leem, and Jung-ok Lee. 2019a. Tongiruisikjosa 2018 [Unification Perception Survey 2018]. Seoul: Institute for Peace and Unification Studies.

Jung, Dong Joon, Kyunghyo Chun, In-chul Moon, Hyun-sook Um, Dong-joon Cho, Kyunghoon Leem, and Jung-ok Lee. 2019b. Bukanjumin tongiruisik 2018 [North Korean Unification Perception Survey 2018]. Seoul: Institute for Peace and Unification Studies.

Jung, HyangJin. 2005. “Talbuk cheongsonyeondeurui gamjeongseonggwa Nambukanui munhwasimnijeok chai” [North Korean Refugees' Emotionality and Its Social Implications: A Perspective from Cultural Psychology]. Bigyomunhwayeongu [Comparative Cultural Studies] 11 (1): 81-111.

Kang, Chae Yeon. 2018. “Bukanitaljumindeurui 'jeongcheseongui iju’ paereodaime gwanhan yeongu" [A Study on the 'Migration of Identity' Paradigm of North Korean Defectors]. Damunhwasahoeyeongu [The Journal of Multicultural Society] 11 (2): 5-36.

Kang, Jin Woong. 2011. "Hanguksimini doendaneun geot: Hangugui gyuyuljeok gabeoneonseuwa talbuk jeongchakjadeurui jeongcheseong bunhwa" [Becoming South Korean: South Korea's Disciplinary Governance and North Korean Settlers' Identity Formation]. Hanguksahoehak [Korean Sociology] 45 (1): 191-227.

Kang, Min-Kyung, Seon-Gi Baek, and Siho Nam. 2017. "Munhwajeok yanggeukwa, talbukja tokeusyo, jeongcheseong hollan: ije mannareo gamnidawa moranbongkeulleobe daehan damhwa mit damnon bunseok" [North Korean Defectors, Talk Shows, Dialogue and Discourses: A Dialogue and Discourse Analysis on TV Talk Shows with North Korean Defectors in South Korea]. Hangukkontencheuhakoenonmunji [Journal of the Korea Contents Association] 17 (1): 567-84.

Kim, Joo Sam. 2016. “Joseonjokgwa Bukanitaljuminui Hanguksahoe jeogeunggwa tongilgwajeongeseoui yeokal" [The Adjustment of Korean Chinese and North Korean Refugees into Korean Society and Their Role in the Process of National Unification]. Diaseupora yeongu [Journal of Diaspora Studies] 10 (2): 291-319.

Kim, Yoo Jung. 2014. “Bukanitaryeoseongui bumohwa gyeongheom” [Parentification Experience of North Korean Women Refugees]. Sahoegwahagyeongu [Journal of Social Science] 40 (2): 77-108.

Kim, You-Yeon, Myung-Ah Son, and Seok-Ho Kim. 2018. "Gajokgwa sahoejeok gwangyega talbukcheongsonyeonui haengboge michineun yeonghyang" [Effects of Family and Social Relations on Happiness of North Korean Adolescent Refugees in South Korea]. Hanguginguhak [Korean Journal of Population Studies] 41 (2): 179-205.

Kwon, Soo Hyun. 2011. "Bukanitaljumine daehan Namhangungminui taedo" [Individual Attitudes toward North Korean Immigrants]. Hangukjeongchiyeongu [Journal of Korean Politics] 20 (2): 129-53.

Kwon, Sookdo. 2018. "Sahoetonghabeul wihan Bukanitaljumin jeongchakjiwonchegye gaeseonbangan jean" [Suggestion of Improvement Plan of Settlement Support System for North Korean Defectors for Social Integration]. Tongiryeongu [Unification Studies] 22 (1): 71-108.

Lankov, Andrei. 2006. "Bitter Tastes of Paradise: North Korean Refugees in South Korea." Journal of East Asian Studies 6 (1): 105-37. 
Lee, Byung Soo. 2014. “Talbukja gachigwanui ijungseonggwa jeongcheseongui bunhwa” [A Duality in North Korean Defectors Value Orientations and Differentiation of Identity]. Tongirinmunhak [The Journal of the Humanities for Unification] 59: 12150.

Lee, Chanhui. 2019. "Bukanjumindo Daehanminguk gungminida” [North Korea Residents are also South Korean Nationals]. Painaensyeollyuseu [Financial News], November 26. https://www.fnnews.com/news/201911261747101240 (accessed January 10, 2020).

Lee, In Hee, and Hee Jung Choi. 2017. "Bukanitaljuminui sahoejeogeunge michineun yeonghyangyoin" [Factors Influencing Social Adaptation of North Korean Defectors]. Hangukbogeonganhohakoeji [Journal of Korean Public Health Nursing] 31 (2): 34151.

Lee, Soo Jung, and Woo Young Lee. 2014. "Yeongguk nyumoldeun koria taun nae Namhanijumingwa Bukannanmin ganui gwangyewa sanghoinsik" [Social Relations and Attitudes between South Korean Migrants and North Korean Refugees in the Korea Town, New Malden, U.K.]. Bukanyeonguhakoebo [North Korean Studies] 18 (1): 137-74.

Lee, Sun-Min. 2014. “Talbugyeoseongeun eotteoke malhalsu inneunga?: tellebijyeon tokeusyo <ije mannareo gamnida> (chaeneol A)e daehan bipanjeok bunseogeul jungsimeuro" [How Can North Korean Women Defectors Speak?: A Critical Analysis of Television Talk Show <Now, Going To Meet> (Channel A)]. Midieo, jendeo \& munhwa [Media, Gender \& Culture] 29 (2): 75-115.

Moon, Seungho. 2010. "Multicultural and Global Citizenship in the Transnational Age: The Case of South Korea." International Journal of Multicultural Education 12 (1): 1-15.

Oh, Won Hwan. 2016. “Talbukja jeongcheseongui jeongchihak: jongpyeoneseoui talbungminyeoui deungjanggwa talbukja jeongcheseongui byeonhwareul jungsimeuro" [The Politics of Identity of North Korean Refugees]. Hangukbangsonghakbo [Korean Journal of Broadcasting and Telecommunication Studies] 30 (3): 5-41.

Park, Myung-Kyu, Byeong-No Kim, Soo-Am Kim, Young-Hoon Song, and Un-Chul Yang. 2011. Noseukorian diaseupora [North Korean Diaspora]. Seoul: Institute for Peace and Unification Studies.

Republic of Korea. 1997. "Protection of Defecting North Korean Residents and Support of Their Settlement Act." 14 July. https://www.refworld.org/docid/3ae6b4ef28.html (accessed May 10, 2020).

Schachter, Elli P. 2005. "Erikson Meets the Postmodern: Can Classic Identity Theory Rise to the Challenge?" Identity 5 (2): 137-60.

Seo, Yu Kyung. 2013. "Hyeonhaeng Bukanitaljumin jiwonjeongchaegui du gaji geunbonmunjewa damunhwajuuijeok sahoetonghap haebeop" [Two Fundamental Problems of the Current Support Policy on North Korean Defectors and Solution for Multiculturalist Social Integration]. Daehanjeongchihakoebo [Korean Political Review] 21 (2): 301-27.

Seol, Jin Bae, and Eun Hee Song. 2017. "Wigiinga gihoeinga?: yanggaseong tamsaegeul tonghan Bukanitaljumin sahoetonghap bangan" [Risk or Opportunity?: Ambivalence and Social Integration among North Korean Refugees]. Crisisonomy 13 (4): 19-43.

Shin, HaeRan. 2019. "Extra-territorial Nation-building in Flows and Relations: North Korea in the Global Networks and an Ethnic Enclave." Political Geography 74: 1-9.

Sohn, Ae-Lee, and Nae-Young Lee. 2012. “Talbukjae daehan hanguginui taedo yeongu: 
Gukgajeongcheseonggwa damunhwasuyongseongeul jungsimeuro" [Study on the Attitude of South Koreans Toward North Korean Defectors: Focusing on National Identity and Multi-Cultural Acceptability]. Ataeyeongu [Journal of Asia-Pacific Studies] 19 (3): 5-34.

Yang, Min Sook, and Dong Hoon Lee. 2017. "Bukanitaryeoseongui saengaesa yeongu” [Study on Life History of a Female North Korean Defector]. Hangukkontencheuhakoenonmunji [Journal of the Korean Contents Association] 17 (10): 120-39.

Yoo, Heasook, and Hyunsook Lee. 2014. "Bukanitaljumingwa Namhanjuminui insik bigyoyeongu" [The Conflict of Recognition Between South Korean and North Korean Refugees: Focused on Incheon City]. Incheonhagyeongu [The Journal of Incheon Studies] 20: 325-65.

Yoon, Bo Young. 2015. "Gyeonggyein ironeul tonghan Namhan jeongchak Bukanitaljumin ihaee gwanhan yeongu" [A Study on a New Methodological Approach for Understanding North Korean Defectors: Focusing on Marginal Man Theory]. Sahoegwahagyeongu [The Journal of Social Sciences] 22 (3): 187-216.

Yoon Gyun-Soo, and Amie Meeae Park. 2016. "Acculturation as a Frustration Negotiation Cycle: North Korean Women Defectors in South Korea." Asian Journal of Women's Studies 22 (4): 462-76.

Yoon, In Jin. 2012. "Bukanijuminui munhwabyeonyonggwa sahoejeogeung” [North Korean Defectors' Appropriation of Culture and Social Adaptation]. Hangukagyeongu [Korean Studies Research] 41: 37-61.

Yoon, In Jin, and Yung Ho Song. 2013. "Bukanijumine daehan Namhanjuminui minjoguisikgwa damunhwauisik" [South Korean Nationalist Perception on North Korean Defectors and Multicultural Perception]. Jaeoehaninyeongu [Overseas Korean Studies] 30: 7-40.

\footnotetext{
Kyung Hyo Chun is a Senior Researcher at the Institute for Peace and Unification Studies (IPUS) at Seoul National University. Before joining the IPUS, she was a Postdoctoral Researcher at the Academy of East Asian Studies, Sungkyunkwan University and a HK Research Professor at the Institute of Humanities for Unification at Konkuk University. She served as Managing Editor for the S/N Korean Humanities from 2015-2016 and is currently Managing Editor for Scopus-indexed Asian Journal of Peacebuilding (AJP). Chun completed her BA (anthropology) at Seoul National University, and MA (anthropology with museum training concentration) at the George Washington University in Washington, D.C. She earned her doctorate in anthropology from the University of British Columbia, Canada. Her areas of research interest include post-coloniality, nationalist discourse, North Korean refugees, commemorations, museum representations, material culture, cultural properties, multiculturalism, and media politics. Email: anth.chun@gmail.com.
} 